\title{
Erratum to: Nuclear imaging of molecular processes in cancer
}

\author{
Rafael Torres Martin de Rosales • Erik Årstad • \\ Philip J. Blower
}

Published online: 20 October 2009

(C) Springer-Verlag 2009

\section{Erratum to: Targ Oncol}

\section{DOI 10.1007/s11523-009-0120-2}

An error occurred in publication of Fig. 3 in the article "Nuclear Imaging of Molecular Processes in Cancer" by R. Torres Martin de Rosales et al. The correct figure and legend follow.

Fig. 3 Structures of imaging agents used to measure hypoxia in tumours; Right: hypoxia in head and neck cancer, visualised with combined PET/CT imaging after administration of ${ }^{64} \mathrm{CuATSM}$, transaxial view

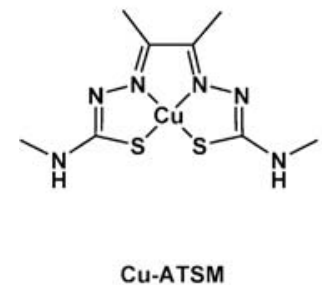

Cu-ATSM<smiles>O=[N+]([O-])c1nccn1CC(O)C[18F]</smiles>

$\left[{ }^{18} \mathrm{~F}\right] \mathrm{FMISO}$

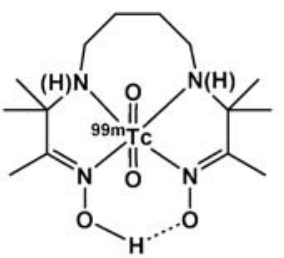

${ }^{99 m}$ TC-HL91

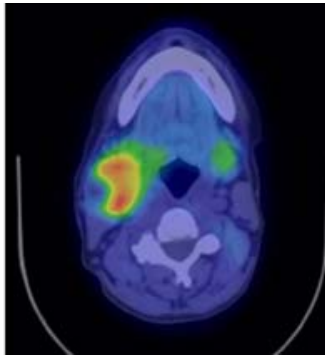

The online version of the original article can be found at http://dx.doi. org/10.1007/s11523-009-0120-2.

R. Torres Martin de Rosales $\cdot$ P. J. Blower $(\square)$

King's College London, Division of Imaging Sciences,

Rayne Institute, St Thomas' Hospital,

4th Floor Lambeth Wing,

London SE1 7EH, UK

e-mail: Philip.Blower@kcl.ac.uk

\section{E. Årstad}

Institute of Nuclear Medicine, University College London,

235 Euston Road,

London NW1 2BU, UK 